Research Article

\title{
Managing traumatic anal sphincter injuries without the use of endo- anal ultrasound: an experience with 29 patients presenting to the surgery department at a tertiary care centre in North India
}

\author{
Parvez David Haque*, Amit Mahajan, Navjot Singh, Rajeev Kapoor, Navneet K. Chaudhry
}

Department of Surgery, Christian Medical College and Hospital Ludhiana Punjab, India

Received: 26 January 2016

Accepted: 29 February 2016

*Correspondence:

Dr. Parvez David Haque,

E-mail: pdhaque@gmail.com

Copyright: (C) the author(s), publisher and licensee Medip Academy. This is an open-access article distributed under the terms of the Creative Commons Attribution Non-Commercial License, which permits unrestricted non-commercial use, distribution, and reproduction in any medium, provided the original work is properly cited.

\begin{abstract}
Background: Endosonography is the method of choice for pre-operative imaging of External Anal Sphincter (EAS), having established its role in identifying sphincter defects. We present here results of sphincter repair done in traumatic external sphincter defects with clinical examinations as the only pre-operative tool, to evaluate and map the sphincter defect as well as to assess the probability of success of the repair.

Methods: The data has been collected from an ongoing prospective study over a period of 5 years (2008 -2013) in patients with fecal incontinence secondary to traumatic anal sphincter injuries detected during initial presentation in acute setting. Clinical assessment was used in isolation to diagnose EAS defect. Contraction of the sphincter on inspection and per rectal examination was done to assess the location of the defect. All patients underwent the usual overlapping sphincter repair with covering stoma under general anesthesia. The location and size of the defect found during surgery was recorded and compared with the clinical findings.

Results: Cohort of 29 patients over a period of 5 years (2008-2013) with traumatic sphincter injury were included in this study who underwent overlapping sphincter repair. (21/29) patients were male patients, road traffic accidents was the most common etiology (23/29) followed by sphincter complex injury related to obstetric and gynaecological procedure (5/29). Majority of patients were managed with fecal diversion (27/29). (24/27) patients had their stoma's reversed and were fully continent. 8 patients developed anal stenosis managed with repeated self-anal dilatation on follow-up.

Conclusions: Pre-operative clinical assessment with intra-operative assessment of the site of sphincter injury is a good clinical tool in detecting the size and site of the defect for surgical repair of injured anal sphincter without using endoanal ultrasonography.
\end{abstract}

Keywords: Endoanal ultrasound, anal sphincter, clinical mapping, sphincter repair RTA-road traffic accidents

\section{INTRODUCTION}

Endosonography is the method of choice for preoperative imaging of External Anal Sphincter (EAS), having an established role in identifying sphincter defects ${ }^{1}$

Sphincter defect mapping helps the surgeon by confirming the exact site and nature of the defect. The physiological function of the sphincter mechanism is assessed by anorectal manometry and pudendal nerve terminal motor latency test. ${ }^{2}$

We present here in our paper results of sphincter repair done in traumatic external sphincter defects with clinical examinations as the only pre-operative tool used to assess and map the sphincter defect as well as to assess the probability of success of the repair. 


\section{METHODS}

The data has been collected from an ongoing prospective study over a period of 5 years $(2008-2013)$ in patients with fecal incontinence secondary to traumatic anal sphincter injuries or traumatic sphincter injuries detected during initial presentation after trauma.

Relevant data pertaining to etiology, duration of injury, fecal incontinence and clinical findings was documented. Clinical assessment was used in isolation at the time of initial presentation to diagnose EAS defect. Contraction of the sphincter on inspection and per rectal examination was done to assess the location of the defect.

All patients underwent the overlapping sphincter repair under general anesthesia. With the patient in prone or supine position, sphincter was identified through a curvilinear incision, scar tissue at injured portion divided, and the internal and external sphincters mobilized together to allow overlapping repair using $1 / 0$ prolene suture. A covering stoma was constructed in all but two patients.

The location and size of the defect found during surgery was recorded and compared with the clinical findings.

\section{RESULTS}

The cohort of patients included those who were admitted under the department of surgery at Christian medical college and hospital, Ludhiana. These patients were assessed by a per rectal examination in casualty followed by examination under anaesthesia in operation theatre at the time of primary repair or at a later stage when the repair was attempted. No further imaging was pursued in these patients. All patients underwent overlapping sphincter repair along with a diverting stoma. Post procedure on follow-up, the patients were kept on Biofeedback exercises, which reflected the recovering sphincter. Stoma reversal was done over a period of 6-18 months with full sphincter recovery.

Majority (21/29) of the patients in our study were male patients, who presented following road traffic accidents; followed by injuries related to birth injuries and gynaecological procedures.
4 patients presented acutely with injury to the sphincters due to road traffic accidents and were reviewed and repaired under anesthesia.

In 29 patients, the preoperative clinical mapping for all patients matched well with operative findings under anaesthesia. The sphincter defect depicted as a pictoral representation matched well with sphincter disruption identified at surgery at time of repair. There 2 patient in which the clinical mapping was off the actual location of defect by about 25\%; however the defect could be approached through the same skin incision.

All but 3 patients of the 27 who had a stoma, have had their stoma's reversed. The 3 patients continue to have poor sphincter control detected on biofeedback exercises. 24 patients have regained good function of their sphincters and are fully continent.

Anal stenosis was seen as a complication in $8 / 24$ patients on follow-up, which was managed with self anal dilatation using metallic dilators.

Table 1: Etiology.

\begin{tabular}{|ll|}
\hline Road traffic accident & $\mathbf{2 3}$ \\
\hline Birth injury & 2 \\
\hline Gynaecological Procedure & 3 \\
\hline Perianal Wound Debridement & 1 \\
\hline
\end{tabular}

Road traffic accidents remain the leading cause of damage to the EAS complex. All patients, except 2 patients (post-delivery) recovered some form of proximal fecal diversion.

Table 2: Operative Records.

\begin{tabular}{|c|c|}
\hline $\begin{array}{l}\text { Overlapping } \\
\text { Repair }\end{array}$ & 29 \\
\hline \multicolumn{2}{|l|}{ Stoma } \\
\hline Sigmoid loop & 22 \\
\hline Transverse loop & 5 \\
\hline No stoma & 2 \\
\hline
\end{tabular}

Table 3: Comparison of external sphincter defects: clinical assessment vs. intra-operative finding.

\begin{tabular}{|lllll|}
\hline $\begin{array}{l}\text { Clinical } \\
\text { pre-operative }\end{array}$ & $\begin{array}{l}\text { Intra-operative } \\
\text { assessment [under } \\
\text { assessment }\end{array}$ & Accuracy $\pm \mathbf{5} \%$ & Accuracy $\pm \mathbf{2 5} \%$ & Not Assessed \\
\hline 29 & 29 & 24 & 2 & 3 (had anal stenosis) \\
\hline
\end{tabular}




\section{DISCUSSION}

For detecting anal sphincter pathology in patients with anal incontinence, Endoanal ultrasound is the investigation of choice. Endoanal ultrasound requires specialized equipment, experience and its relative invasiveness has led to the development of other alternative imaging modalities like transvaginal and transperineal ultrasound. In the last few decades, anal sphincter complex has been the favourite central subject to be discussed among the specialties which includes colorectal surgeons, gastroenterologists, radiologists and obstetricians. Division of the anal sphincters occurs as a result of traumatic injury, surgical mishappening, or following obstetric tears extending into the anal canal, with varying degree of anal incontinence for which the patients require colostomy as initial approach for treatment. Clinical examination as the only tool of mapping the sphincter damage along with operative examination findings at the time of repair, in the absence of endoanal ultrasound with good results in our cohort of patients appears to be an attractive option.

Endoanalsonography (EAS) was first described by Law and Bartram using a B\&K type 1846 (Bruel \& Kjaer, Naerum, Denmark) ultrasonographic scanner with a 7 $\mathrm{MHz}$ rotating endoprobe along with describing the sonographic anatomy of five layers of the anal canal i.e. mucosa, submucosa, internal anal sphincter, intersphincteric plane and external anal sphincter. ${ }^{3}$ Sultan et al demonstrated the normal sonographic anal sphincter anatomy along with differentiating features with respect to males and females. Histological confirmation was made, further comparing the sonographic images of sphincter defects especially external anal sphincter and establishing a $100 \%$ accuracy of sphincter defects as against clinical assessment by colorectal surgeons (50\%), manometry $(75 \%)$ and electromyography $(75 \%) .^{4-6}$. Anal endosonography is currently the diagnostic tool of choice in the investigation of anal incontinence; twodimensional (2D) and three-dimensional (3D) volumetric endovaginal ultrasound (EVUS) and transperineal ultrasound (TPUS), proposed as alternative imaging modalities to describe anal sphincter integrity. Division of the anal sphincters presents problems in primary management, re-establishment of continence, and social rehabilitation, the most challenging being restoration of anal continence. Primary repair during the time of injury is usually successful following obstetric tears limited to the anterior midline, but the failure rates are high when done following traumatic or operative injury elsewhere in the sphincter ring. In our series 4 patients were immediately managed with primary repair with a covering stoma in only 2 of the patients, recovering good anal continence on follow-up.

Residual sphincter defects remain in most and around $50 \%$ remain incontinent. In our case series 26/29 $(89.65 \%)$ patients were continent at the time of stoma reversal and follow-up, with only 3 patients (10.34\%) still having anal incontinence with non-reversal of stoma. Numerous techniques addressing repair of sphincter injury have been reported in literature classified as indirect and direct methods. Indirect techniques consisting of constructing circumanal slings of striated muscle or fascia, external sphincter reefing procedures and the use of striated muscle grafts. Direct methods includes identification, mobilization, and suture repair of the divided ends of the sphincter using end to end technique but these techniques have some drawbacks in the form of sutures cutting out and muscle ends retracting leading to initial disappointment results. This led to the use of an alternative method of direct repair utilizing an overlapping technique, providing good functional results. $^{7-10}$ In our cohort of 29 patients, all underwent overlapping anal sphincteroplasty with only 3 patients $(10.34 \%)$ still having anal incontinence. We also encountered anal stenosis in 8 patients on follow-up which was managed with anal dilatation using metallic dilators

\section{CONCLUSION}

There is a male preponderance amongst patients with anal sphincter injuries. Road traffic accidents were the leading cause of injury to anal sphincters. Fecal diversion as a covering stoma was essential in $86.20 \%$ of patients. Over-lapping anal sphincter repair was well tolerated by most patients. Anal stenosis as a complication was encountered in $8 / 24$ patients $(33.33 \%)$ managed nonoperatively during follow-up. Pre-operative clinical assessment correlated well with intra-operative assessment of the site of sphincter injury, and is a good clinical tool in detecting the size and site of the defect for surgical repair of the sphincter without using endoanal ultrasonography.

\section{Funding: No funding sources Conflict of interest: None declared \\ Ethical approval: The study was approved by the institutional ethics committee}

\section{REFERENCES}

1. Romano G, Rotondano G, Esposito P, Pellecchia L, Novi A. External anal sphincter defects: correlation between pre-operative anal endosonography and intraoperative findings. $\mathrm{Br} \quad \mathrm{J}$ Radiol. 1996;69(817):6-9.

2. Halverson AL, Hull TL. Long term Outcome of Overlapping Anal Sphincter Repair. Dis Colon Rectum. 2002;45(3):345-8.

3. Law PJ, Bartram CI. Anal Endosonography: technique and normal anatomy. Gastrointest Radiol. 1989;14:349-53.

4. Sultan AH, Kamm MA, Hudson CN, Nicholls JR, Bartram CI. Endosonography of the anal sphincters: normal anatomy and comparison with manometry. Clin Radiol. 1994;49:368-74. 
5. Sultan AH, Kamm MA, Talbot IC, Nicholls RJ, Bartram CI. Anal Endosonography for identifying external sphincter defects confirmed histologically. Br J Surg. 1994;81:463-5.

6. Sultan AH. The role of Anal Endosonography in obstetrics. Ultrasound Obstet Gynecol. 2003;22:559-560.

7. Parks AG, Mc Partlin JF. Late repair of injuries of the anal sphincter. Proc R Soc Med. 1971;64:11879.
8. Browning GGP, Motson RW. Anal sphincter injury; Management and result of Parks sphincter repair. Ann Surg. 1984;199:351-7.

9. Fang DT, Nivatvongs S, Vermeuken FD et al. Dis colon rectum 1984;27:720-22.

10. Keighley MRB, Fielding JWL. Management of faecal incontinence and results of surgical treatment. Br J Surg. 1984:70:463-8.

Cite this article as: Haque PD, Mahajan A, Singh N, Kapoor R, Chaudhry NK. Managing traumatic anal sphincter injuries without the use of endoanal ultrasound: an experience with 29 patients presenting to the surgery department at a tertiary care centre in North India. Int Surg J 2016;3:697700 . 